\title{
Current status of the diagnosis and treatment of gastrointestinal schwannoma (Review)
}

\author{
ZHIYONG QI, NAIXV YANG, MENGQI PI and WEI YU \\ Department of Gastrointestinal, Colorectal and Anal Surgery, China-Japan Union \\ Hospital of Jilin University, Changchun, Jilin 130033, P.R. China
}

Received August 25, 2020; Accepted December 23, 2020

DOI: $10.3892 / 01.2021 .12645$

\begin{abstract}
Gastrointestinal schwannoma is a rare, slow-growing and benign tumor that mostly originates in the Auerbach myenteric nerve plexus in the gastrointestinal tract. The clinical manifestations may be associated with the location, size, differentiation type, and degree of malignancy of the tumor. Endoscopy, ultrasound and imaging examinations serve an important auxiliary role in the clinical identification, diagnosis and differential diagnosis of lesions; assessment of risk; and preparation for surgery. S-100 positivity is a hallmark of schwannoma. CD34, CD117, discovered on GIST-1, P53, ALK, $\beta$-catenin, smooth muscle actin and Desmin negativity are helpful for the identification of other gastrointestinal stromal tumors. Surgical removal of the tumor is the main treatment for schwannoma. Benign gastrointestinal schwannoma has a good prognosis without recurrence and metastasis; malignant transformation is extremely rare and has a poor prognosis.
\end{abstract}

\section{Contents}

1. Introduction

2. Pathogenesis

Correspondence to: Dr Wei Yu, Department of Gastrointestinal, Colorectal and Anal Surgery, China-Japan Union Hospital of Jilin University, 126 Xiantai Street, Changchun, Jilin 130033, P.R. China E-mail: yu_wei@jlu.edu.cn

Abbreviations: GIS, gastrointestinal schwannoma; GIMS, gastrointestinal malignant schwannoma; GIST, gastrointestinal stromal tumor; NF1, neurofibromatosis type 1; NF2, neurofibromatosis type 2; EUS-FNA, endoscopic ultrasound-guided fine-needle aspiration; EUS-TCB, endoscopic ultrasound-guided fine-needle aspiration; CT, computed tomography; MRI, magnetic resonance imaging; ${ }^{18} \mathrm{FDG}-\mathrm{PET},{ }^{18}$ fluorodeoxyglucose positron emission tomography; LECS, laparoscopic and endoscopic cooperative surgery; NSE, neuron-specific enolase; DOG-1, discovered on GIST-1; GFAP, glial fibrillary acidic protein; SMA, smooth muscle antigen; HMB-45, human melanoma black45; LCA, leucocyte common antigen; PCNA, proliferating cell nuclear antigen

Key words: GIS, GIST, S-100, LECS

\author{
3. Clinical features \\ 4. Common auxiliary examinations and characteristics \\ 5. Pathological characteristics \\ 6. Differential diagnosis \\ 7. Treatment \\ 8. Prognosis \\ 9. Conclusion
}

\section{Introduction}

Schwannomas are caused by the excessive proliferation of Schwann cells in nerve sheaths. They grow slowly and can occur in any part of the body, such as the limbs, head, spinal cord and peripheral nerves of the central nervous system, but are rarely seen in the gastrointestinal tract (1). Gastrointestinal schwannoma (GIS) was first reported by Daimaru in 1988 (2), and it is being diagnosed more frequently with recent advances in diagnostic technology and immunohistochemistry. Schwannomas account for $2-6 \%$ of gastrointestinal mesenchymal tumors $(3,4) ; 60-70 \%$ occur in the stomach, followed by the colon and rectum (3\%), and their occurrence in the esophagus and small intestine is even rare (5). They are classified as mesenchymal or neuroectodermal tumors, and this type of tumor originates in the gastrointestinal wall and includes gastrointestinal schwannoma (GIS), gastrointestinal stromal tumor (GIST), leiomyoma, leiomyosarcoma, neurofibroma, lipoma, ganglioneuroma, paraganglioma, granulosa cell tumor and globular tumor. GIS originates from the Auerbach myenteric plexus in the gastrointestinal nerve plexus (2). The most common clinical feature is submucosal lesions, which are usually found accidentally during gastrointestinal endoscopy, endoscopic ultrasonography, imaging or abdominal surgery. However, so far, due to its low incidence, malignant transformation occurs in only $2 \%$ of cases (6), it has not been studied comprehensively enough, and most reports on GIS are case reports. The diagnostic accuracy is diminished by the morphological diversity of GIS, and it is difficult to develop a unified diagnostic standard (7-12). The clinical manifestations, commonly used laboratory examinations, pathological features, differential diagnosis, treatment and prognosis were reviewed, aiming to provide a reference for GIS diagnosis and treatment. 


\section{Pathogenesis}

Molecular mechanism. The pathogenesis of schwannomas is not yet fully understood. Studies have been limited to classic soft tissue schwannomas (such as vestibular nerves and trigeminal schwannomas), which are mostly associated with genetic diseases, such as neurofibromatosis type 2 (NF2) defects, and involve the process of chronic peripheral nerve injury and over-repair (13-15). When peripheral nerves are damaged, Schwann cells in a static state are activated to initiate a redifferentiation program for repair; however, if the NF2 gene is abnormal, large numbers of Schwann cells will proliferate due to the disruption of redifferentiation, which will eventually lead to tumor formation (16). Lasota et al (17) found that NF2 in GIS exhibited the loss of heterozygosity, and inactivating mutations were identified in only 1 of 20 analyzed tumors.

Gastrointestinal malignant schwannoma (GIMS) may be associated with neurofibromatosis type 1 (NF1). In the study of NF1, it has been shown that NF1 gene mutations and/or the loss of heterozygosity may exist in 50\% of GIS (17), resulting in the loss of neurofibrin (encoded by NF1), thereby accelerating the inactivation of Ras GTP and leading to increased RAS expression. The interaction between the loss of neurofibrin and the increase in RAS expression leads to the enhancement of mitotic signals and dysregulation of cell cycle growth regulation, promoting tumor malignancy (18).

\section{Clinical features}

The age of GIS occurrence is mostly between 50 and 80 years (5). Some studies have reported that GIS occurrence has a female preponderance $(2,6,10)$. GIS is occasionally seen in gastrointestinal endoscopy and imaging examinations; these tumors are mostly benign with relatively slow growth, which causes nonobvious gastrointestinal symptoms in most patients. The corresponding symptoms depend on the tumor location, size, differentiation, and degree of malignancy.

When the tumor occurs in the stomach, it often causes upper abdominal discomfort, including atypical abdominal pain, fullness, nausea, acid reflux, vomiting and anorexia; if the tumor develops in a certain location, such as the cardia and pylorus, as the tumor expands, it can cause eating obstruction, nausea and vomiting. In the intestine, the tumor can cause obstruction, intussusception and melena, as the tumor grows through the mucosa and forms an ulcer. The excessive growth of GIS may involve other organs and cause corresponding symptoms, such as large gastric schwannoma that causes atypical chest pain (19), pleural effusion (20) and other unique symptoms. In general, a tumor size in the gastrointestinal tract over $5 \mathrm{~cm}$ is known to have a high risk of possible complications and thus needs curative resection; if not resected, the propensity to become malignant is high.

When tumor growth causes compression or ischemic necrosis, acute symptoms, such as abdominal pain, obstruction, bleeding, perforation and other clinical manifestations, may appear. Some cases have also reported schwannoma causing intussusception (21). In addition, as a benign tumor, it can also cause symptoms associated with malignant tumors. Case reports have also found that GISs can cause
Lambert-Eaton myasthenia-like syndrome (22) and other paraneoplastic syndromes; other symptoms can also include secondary membranous nephropathy (23), proteinuria and lower extremity edema.

At present, there are few reports on GIMS, and their symptoms can be similar to those of benign tumors, but malignant behaviors such as metastasis and cachexia may also occur (24-27).

\section{Common auxiliary examinations and characteristics}

Digestive tract (ultrasound) endoscopy, abdominal ultrasound, computed tomography (CT), magnetic resonance imaging (MRI), ${ }^{18}$ fluorodeoxyglucose positron emission tomography $\left({ }^{18}\right.$ FDG-PET) and other examinations are routine examinations for gastrointestinal diseases. For GIS that resembles as other common tumors of the bowel, the aforementioned examinations are nonspecific, not pathognomonic, and only provide a reference for diagnosis $(28,29)$.

Endoscopy and ultrasound endoscopy. Gastrointestinal endoscopy is one of the most common examinations of the digestive tract. It can clarify the location, size, and mucosal changes of GIS; however, considering that GIS mostly occurs in the muscularis propria or submucosa, it mostly appears as protruding lesions under endoscopy, so patients are mostly treated for GIST. Conventional endoscopic tissue biopsy usually only shows chronic inflammatory manifestations of the mucosa, so it is difficult to diagnose tumors. Twenty-five to $50 \%$ of tumors will cause ulcers in the central area as the volume increases, leading to ischemic changes in the surrounding mucosa (30). Similarly, GIMS also involves bleeding from malignant ulcers, so bleeding, necrosis, and ulcer changes can provide help in identifying benign and malignant tumors.

Endoscopic ultrasound-guided biopsy is currently an important examination for the preoperative diagnosis of gastrointestinal tumors, especially submucosal tumors, and increases the chances of preoperative diagnosis by $10 \%(31,32)$. It generally includes endoscopic ultrasound-guided fine-needle aspiration and trucut biopsy (EUS-FNA and EUS-TCB), but there are significant differences in the number of tissue samples obtained due to differences in puncture techniques, so the specificity of EUS-FNA and EUS-TCB is low (52 vs. 55\%) (33). The latest research found that using EUS-FNA-derived RNA for mutation analysis is highly feasible and provides reliable results (34); therefore, for submucosal GIS, ultrasound-guided biopsy is recommended as a routine examination method to confirm the preoperative diagnosis.

Ultrasound examination. Abdominal ultrasound examination is currently widely used to locate abdominal masses and evaluate blood flow conditions. Contrast-enhanced ultrasound is a non-invasive inspection method that does not use radiation to examine the perfusion status of the lesion. Because it can examine the blood perfusion of a tumor, it is very useful in the differential diagnosis of lesions (35). Under ultrasound, GIS mostly appear as hypoechoic masses with clear boundaries and insufficient internal blood flow. When contrast-enhancing agents are used for enhanced dynamic imaging, gastric 
schwannoma exhibits a rapidly progressing washout phenomenon, while on static images, the tumor appears with moderate echo enhancement (36).

Abdominal computed tomography (CT) and magnetic resonance imaging (MRI). GISs can occur in any part of the gastrointestinal tract, and most of them grow contralaterally to the mesenteric attachment (37). Under CT, it mostly appears round, with uniform density or density lower than soft tissue and clear boundaries. A homogeneous pattern of tumor attenuation is the most consistent feature of GIS on CT scans. However, there are also a small number of cases with slow and progressive enhancement, suggesting that the enhancement of gastrointestinal schwannomas occurs over time, with peak enhancement occurring during the equilibrium phase (38). The most striking difference in the CT features of GIS compared with those of GIST is the rare presence of hemorrhage, necrosis and cystic changes. It shows fewer signs of abdominal parenchymal organs, lymph node malignant metastasis and abdominal effusion, which is helpful for the differentiation of benign and malignant tumors. Compared with CT examination, MRI is superior to CT in distinguishing GIS and GIST. On T1-weighted images, tumors often show lower signal intensity, while on T2-weighted images, they often show higher signal intensity (39).

${ }^{18} F D G-P E T$. FDG-PET is mainly used to assess the malignant potential of tumors and the recurrence and metastasis of malignant tumors. It is one of the important preoperative methods for distinguishing benign and malignant lesions from atypical gastrointestinal tumors. A previous report demonstrated that benign GIS showed increased FDG intake and large metabolic changes, which contrasted with the low metabolic changes of benign tumors on FDG-PET (40). Miyake et al (41) proposed that this observation may be associated with the lymphatic sheath around the tumor, but there is no relevant experimental evidence. Therefore, the role of FDG-PET in the assessment of benign and GIMS and their differentiation from other interstitial tumors needs further study. FDG-PET may be of limited value as a preoperative diagnostic technique for the assessment of GIS.

Hematological examinations. When tumors cause hemorrhage, decreases in hemoglobin and albumin levels might occur in patients with GIS. Reports have shown that common serum tumor markers, such as fetoprotein, CEA and carcinoembryonic antigen, were within the normal range $(42,43)$, but occasionally increased CA19-9 was observed (44). Notably, Shu et al (45) pointed out that one patient had elevated serum neuron-specific enolase (NSE) levels. NSE is an acid protease that is specific to neurons and neuroendocrine cells, and is highly concentrated in nerve cells, neuroendocrine cells and tumor cells (45). Therefore, it is feasible that the immunohistochemistry of GIS would show a positive NSE result.

\section{Pathological characteristics}

General features. GIS mostly exhibits exogenous or intraluminal bulging growth, with sizes between $<1-28 \mathrm{~cm}(3,5)$; most of them occur as single tumors, and multiple tumors are rare (46). The solid mass is round or oval to the naked eye, with clear boundaries, a gray or yellowish-white cut surface, no intact surrounding capsule, and necrosis, hemorrhage, calcification, and cystic changes in the central area are rare.

Cytological characteristics. Classic soft tissue schwannomas have two alternating structures. Antoni A is a dense growth of spindle cells arranged in a fence-like structure to form Verocay bodies with abundant blood vessels, and Antoni $\mathrm{B}$ is characterized by a loose distribution of spindle cells with round or slender nuclei, containing a large amount of myxoid stroma and xanthomatous histiocytes (47). However, Bohlok et al (6) found that only $12.5 \%$ of cells have two structures in the GIS, with only a structure similar to Anotoni A lacking Verocay bodies. Microscopically, the short spindle cells in GIS are arranged in a palisade shape with unclear borders, their cytoplasm is slightly eosinophilic, and their nucleus is deep and round or oval. The most significant feature of GIS is the short spindle cell in the center of the tumor and the chronic inflammatory cell infiltration around the tumor, forming a prominent lymphoid cuff, which can aid in distinguishing GIS from other mesenchymal tumors. Nuclear atypia with hyperchromasia is common, and the mitotic count rarely exceeds 5/50 high-powered field, which can be used as a standard for the classification of benign and malignant tumors $(6,47,48)$.

Immunohistochemistry. Immunohistochemical examination is the gold standard for diagnosing GIS. S-100 is a group of highly acidic calcium-binding proteins that are widely distributed in neural crest cells and their tumors. Because the Antoni A-like area in GIS can show the diffuse and strong expression of S-100, the strong positivity of S-100 makes it a specific marker, with an expression rate of 97.9\% (6). In addition, CD34 and Vimentin are occasionally positive, and other immunological markers, NSE, CD34, CD117, discovered on GIST-1 (DOG-1), P53, ALK, $\beta$-catenin, smooth muscle antigen (SMA) and Desmin negativity, provide the main evidence for differential diagnosis (46). In addition, GIS derived from non-Schwann cells may be positive for specific markers, such as melanin, which is indicative of melanoma schwannoma. For GIMS, the degree of invasion is mostly associated with the Ki-67 index. It is generally believed that $\mathrm{Ki}-67>5 \%$ is considered to be malignant, and $>10 \%$ is considered to be malignant $(3,5)$. However, Ki-67 alone is not enough to judge the degree of tumor malignancy. It is also necessary to consider factors such as the tumor size, mitotic index, MIB-1, tumor recurrence, and local or distant metastasis (49-52).

GIMS is positive for glial fibrillary acidic protein, vimentin, NSE and CD68, and negative for S-100, CD117, CD 99, CD34, CD20, desmin and SMA (53).

Malignant schwannomas mostly contain dedifferentiated Schwann cells, and the synthesis of s-100 is decreased, so the expression of s-100 will decrease as the malignancy of schwannomas increases (54).

\section{Differential diagnosis}

GIS is a type of gastrointestinal mesenchymal tumor. Due to its low incidence, the clinical misdiagnosis rate is up to 
Table I. Differential diagnosis of GIS by immunohistochemistry.

\begin{tabular}{|c|c|c|c|c|c|c|c|}
\hline & GIS & GIMS & GIST & Neurofibromas & Melanoma & Leiomyomas & Leiomyosarcoma \\
\hline S-100 & +++ & $+\downarrow$ & - & $+/++$ & ++ & - & - \\
\hline Vimentin & +++ & + & - & $+/++$ & ++ & ++ & ++ \\
\hline NSE & ++ & + & - & ++ & - & - & - \\
\hline Desmin & - & & & & & +++ & +++ \\
\hline CD34 & - & & ++ & ++ & - & - & ++ \\
\hline CD117(c-KIT) & - & - & ++ & & \pm & - & - \\
\hline DOG-1 & - & & +++ & & & & - \\
\hline CD56 & +++ & & - & - & & - & - \\
\hline CD68 & +++ & & & - & & & \\
\hline GFAP & + & + & - & - & & - & \\
\hline SMA & - & $\pm^{\mathrm{a}}$ & & & & +++ & +++ \\
\hline HMB-45 & & & & & +++ & & \\
\hline LCA & & - & & & - & & \\
\hline PCNA & & & & & & + & +++ \\
\hline
\end{tabular}

$\downarrow$, Expression decreases as the degree of malignancy increases. ${ }^{a}$ Negative (26) or positive (27) are reported. GIS, gastrointestinal schwannoma; GIMS, gastrointestinal malignant schwannoma; GIST, gastrointestinal stromal tumor; NSE, neuron-specific enolase; DOG-1, discovered on GIST-1; GFAP, glial fibrillary acidic protein; SMA, smooth muscle antigen; HMB-45, human melanoma black45; LCA, leucocyte common antigen; PCNA, proliferating cell nuclear antigen.

$96.7 \%$ (55). The immunohistochemistry features of GIS GISTs and other tumors are described in Table I.

GIST. Due to the prevalence, clinical symptoms, morphology and growth patterns of GIST being very similar to those of GIS, GIS is most commonly misdiagnosed as GIST, and $10-30 \%$ of GIST becomes malignant (56). Therefore, the ability to correctly identify the nature of the tumor plays a key role in further treatment and prognosis. Preoperative imaging and endoscopy can provide limited help, but if GIS is not accurately diagnosed, clinicians usually treat it as GIST. Generally, GIST tumors have a cut surface that is gray or gray-red, rich blood supply, necrosis, liquefaction, calcification, and are commonly cystic, and the behavior is very different from that of GIS. Microscopically, it is composed of spindle cells with diverse morphological arrangements and no palisade shape. CT shows obvious enhancement, and the immunohistochemical phenotype is CD117, CD34 and DOG-1 positivity, and S-100 negativity, which is the most important distinction from schwannoma.

Gastrointestinal smooth muscle tumor. It rarely occurs in the colon and very rarely in the small intestine. The CT findings are often uneven and obviously enhanced. The interior of leiomyoma is gray, solid, fibrous and tough. The cut surface of the leiomyoma can be gray-red and resemble fish flesh, accompanied by hemorrhagic necrosis and cystic degeneration. Microscopically, the spindle cells appear weaved or bundled, and leiomyosarcoma cells have obvious atypia, accompanied by obvious necrosis and mitosis. No muscle-derived markers are positive, and S-100 is negative or weakly positive.
Gastrointestinal lymphoma. Due to the lymphocyte cuff of GISs, they are easily misdiagnosed as gastrointestinal lymphoma during preoperative needle biopsy (57), and CT findings of gastrointestinal lymphoma are similar to those of GIS, so it is not uncommon to misdiagnose GISs as lymphoma. Gastrointestinal lymphoma is usually accompanied by extensive mesenteric or retroperitoneal lymphadenopathy, whose features can be distinguished from GIS. Additionally, gastrointestinal lymphomas are commonly accompanied by adenopathy in the supporting mesenteries and retroperitoneum, so adenopathy is a helpful distinguishing feature for lymphoma (58).

Malignant tumors of the gastrointestinal tract. These tumors grow aggressively and are not clearly demarcated from the normal gastrointestinal wall. They are characterized by a stiff tubular wall, narrow lumen, early gastrointestinal obstruction and local lymphadenopathy. The GIS boundary is clear, lymph nodes are rarely enlarged, and digestive tract obstruction appears late. Since gastrointestinal cancer mostly originate in the mucosal layer, the nature of gastrointestinal malignant tumors can be determined by endoscopic biopsy pathological examination, gastrointestinal cancer can be diagnosed by preoperative pathological examination.

\section{Treatment}

Since the preoperative diagnosis of GIS is often unclear, there is no unified standard for the treatment of schwannomas, but it is clinically believed that the active surgical treatment of schwannomas has been validated. According to the size and location of the tumors and their association with surrounding 
tissues, common surgical methods include endoscopic resection and laparoscopic and open surgery.

Endoscopic resection is often suggested for tumors $<3 \mathrm{~cm}$ in diameter (59). Common surgical types include endoscopic mucosal resection (60) and full-thickness endoscopic surgery resection. However, since the tumor grows under the mucosa, the use of endoscopic resection increases the risk of bleeding, perforation and gastrointestinal fistula. There is no clear evidence that endoscopic resection may lead to incomplete tumor resection and recurrence of residual tumor risks such as metastasis. However, in recent years, new technologies for endoscopic resection have been developed, such as extraluminal endoscopic submucosal tunnel resection (61), which has improved the safety and cure rate of endoscopic resection. Endoscopic resection is not recommended for patients with deep locations, unclear tumor boundaries and metastases.

Surgical resection is currently the most effective way to treat GIS. Common surgical methods include simple tumor resection and partial gastric (intestinal) resection. Experts have reached a consensus that tumor lymph node metastases may be rare, so routine lymph node dissection is not recommended. With the development and popularization of laparoscopic technology, the laparoscopic replacement of traditional open surgery has been accepted by an increasing number of clinicians. Laparoscopic and endoscopic cooperative surgery (LECS) refers to the simultaneous application of laparoscopy (hard scope) and endoscopy (soft scope) during an operation (62). LCES makes up for the shortcomings of a single surgical method. Huang et al (63) reported that the endoscopy-assisted laparoscopic resection group was superior to the laparoscopy group, in terms of a shorter operation time, decreased intraoperative bleeding, short postoperative intestinal function recovery time, and a shortened length of hospitalization $(\mathrm{P}<0.05)$. For tumors $<30 \mathrm{~mm}$ in diameter, a modified LECS technique called 'closed LECS' was created by Kikuchi et al (59) to avoid the potential risk of gastric contents or tumor cells spilling into the abdominal cavity. Therefore, LECS compensated for the inaccurate positioning of the tumor by single-line laparoscopic surgery or the increased risk of bleeding and perforation caused by single-line endoscopic resection, decreases the contaminated area of the operation, lowers the possibility of luminal stenosis, increases safety and is beneficial for the patient's postoperative recovery.

Due to the large difference between the location and volume of GIS, special surgical methods, such as Billroth II (21), may be used for symptoms such as a unique tumor location, severe obstruction, bleeding, large size and compression of other organs. For individuals with diagnosed GIMS, surgical resection, radiotherapy and chemotherapy are recommended (52).

\section{Prognosis}

After the long-term follow-up of patients with benign schwannoma, no recurrence was found after complete tumor resection. As suggested by a longitudinal study, GIMS has a poor prognosis, as 3 out of 10 patients died due to the metastasis or recurrence of GIMS within 5 years after surgery (64). Bevacizumab is an anti-vascular endothelial factor monoclonal antibody that has been shown to effectively inhibit tumor development. It is one of the few drugs for the treatment of schwannomas and has been used in vestibular schwannomas (65). Currently, the effectiveness of molecular therapy for GIMS is unclear because of the very low number of reported cases. Further molecular therapy research will be useful for determining its usefulness in the treatment of GIMS.

\section{Conclusion}

GIS is an uncommon, slow-growing and benign gastrointestinal interstitial tumor that may become malignant in a few cases. Most of these tumors have no obvious specific symptoms or signs. Endoscopy, imaging and ultrasound examinations play a role in differential diagnosis, and biopsy can improve the accuracy of diagnosis. Positivity for S-100 is the gold standard for diagnosing GIS. GIS currently has a relatively high rate of clinical misdiagnosis, resulting in the relatively limited selection of surgical procedures. Complete surgical removal of the tumor is the main method of treatment for GIS. LECS has obvious advantages in the treatment of GIS and is worth recommending.

\section{Acknowledgements}

Not applicable.

\section{Funding}

The present study was funded by the Natural Science Foundation of Jilin Province, China (grant no. 20190201085JC).

\section{Availability of data and materials}

All data sets generated and/or analyzed during the study are available from the authors on reasonable request.

\section{Authors' contributions}

WY conceived the main idea and designed and created the main theoretical parts of this review. ZQ, NY and MP contributed to the design and implementation of research and to writing the manuscript. NY and MP searched and filtered references and suggested the contents of tables. ZQ, NY and MP proofread the manuscript and revised the manuscript for intellectual content. WY and ZQ confirmed the authenticity of all the raw data. All authors read and approved the final manuscript.

\section{Ethics approval and consent to participate}

Not applicable.

\section{Patient consent for publication}

Not applicable.

\section{Competing interests}

The authors declare that they have no competing interests. 


\section{References}

1. Fotiadis CI, Kouerinis IA, Papandreou I, Zografos GC and Agapitos G: Sigmoid schwannoma: A rare case. World J Gastroenterol 11: 5079-5081, 2005.

2. Daimaru Y, Kido H, Hashimoto H and Enjoji M: Benign schwannoma of the gastrointestinal tract: A clinicopathologic and immunohistochemical study. Hum Pathol 19: 257-264, 1988.

3. Nonose R, Lahan AY, Santos Valenciano J and Martinez CA: Schwannoma of the colon. Case Rep Gastroenterol 3: 293-299, 2009.

4. Tsunoda C, Kato H, Sakamoto T, Yamada R, Mitsumaru A, Yokomizo H, Yoshimatsu K, Ogawa K, Aiba M and Haga S: A case of benign schwannoma of the transverse colon with granulation tissue. Case Rep Gastroenterol 3: 116-120, 2009.

5. Zhang K, Qu S, Li J, Cheng Y, Shi J and Liu T: A case report of rectal schwannoma treated with laparoscopic proctectomy. Medicine (Baltimore) 97: e9866, 2018.

6. Bohlok A, El Khoury M, Bormans A, Galdon MG, Vouche M, El Nakadi I, Donckier V and Liberale G: Schwannoma of the colon and rectum: A systematic literature review. World J Surg Oncol 16: 125, 2018.

7. Liegl B, Bennett MW and Fletcher CD: Microcystic/reticular schwannoma: A distinct variant with predilection for visceral locations. Am J Surg Pathol 32: 1080-1087, 2008.

8. Rodriguez FJ, Folpe AL, Giannini C and Perry A: Pathology of peripheral nerve sheath tumors: Diagnostic overview and update on selected diagnostic problems. Acta Neuropathol 123: 295-319, 2012

9. Agaimy A and Wuensch PH: Perineurioma of the stomach. A rare spindle cell neoplasm that should be distinguished from gastrointestinal stromal tumor. Pathol Res Pract 201: 463-467, 2005.

10. Hornick JL and Fletcher CD: Intestinal perineuriomas: Clinicopathologic definition of a new anatomic subset in a series of 10 cases. Am J Surg Pathol 29: 859-865, 2005.

11. Kelesidis T, Tarbox A, Lopez M and Aish L: Perineurioma of esophagus: A first case report. Am J Med Sci 338: 230-232, 2009.

12. Emanuel P, Pertsemlidis DS, Gordon R and Xu R: Benign hybrid perineurioma-schwannoma in the colon. A case report. Ann Diagn Pathol 10: 367-370, 2006.

13. Mautner VF, Lindenau M, Baser ME, Hazim W, Tatagiba M, Haase W, Samii M, Wais R and Pulst SM: The neuroimaging and clinical spectrum of neurofibromatosis 2 . Neurosurgery 38 880-886, 1996

14. Salzer JL and Bunge RP: Studies of Schwann cell proliferation. I. An analysis in tissue culture of proliferation during development, Wallerian degeneration, and direct injury. J Cell Biol 84 739-752, 1980.

15. Tikoo R, Zanazzi G, Shiffman D, Salzer J and Chao MV: Cell cycle control of Schwann cell proliferation: Role of cyclin-dependent kinase-2. J Neurosci 20: 4627-4634, 2000.

16. Helbing DL, Schulz A and Morrison H: Pathomechanisms in schwannoma development and progression. Oncogene 39: 5421-5429, 2020.

17. Lasota J, Wasag B, Dansonka-Mieszkowska A, Karcz D, Millward CL, Ryś J, Stachura J, Sobin LH and Miettinen M: Evaluation of NF2 and NF1 tumor suppressor genes in distinctive gastrointestinal nerve sheath tumors traditionally diagnosed as benign schwannomas: S study of 20 cases. Lab Invest 83: 1361-1371, 2003.

18. Zhang J, Guenther MG, Carthew RW and Lazar MA: Proteasomal regulation of nuclear receptor corepressor-mediated repression. Genes Dev 12: 1775-1780, 1998.

19. Albshesh A, Kaufmann MI and Levy I: Gastric schwannoma. Clin Gastroenterol Hepatol 18: e142-e143, 2020.

20. Janowitz P, Meier F and Reisig J: Gastric schwannoma as a rare differential diagnosis of pleural effusion. Z Gastroenterol 40: 925-928, 2002

21. Yang JH, Zhang M, Zhao ZH, Shu Y, Hong J and Cao YJ: Gastroduodenal intussusception due to gastric schwannoma treated by Billroth II distal gastrectomy: One case report. World J Gastroenterol 21: 2225-2228, 2015.

22. Patanella AK, Bianco A, Federico F, Modoni A, Tonali PA and Batocchi AP: Lambert-Eaton myasthenic syndrome associated with gastric schwannoma. Muscle Nerve 41: 569-570, 2010.

23. Zhang Z, Gong T, Rennke HG and Hayashi R: Duodenal schwannoma as a rare association with membranous nephropathy: A case report. Am J Kidney Dis 73: 278-280, 2019.
24. Loffeld RJ, Balk TG, Oomen JL and van der Putten AB: Upper gastrointestinal bleeding due to a malignant Schwannoma of the stomach. Eur J Gastroenterol Hepatol 10: 159-162, 1998.

25. Watanabe A, Ojima H, Suzuki S, Mochida Y, Hirayama I, Hosouchi Y, Nishida Y, Kashiwabara K, Ohno T, Mochiki E and Kuwano $\mathrm{H}$ : An individual with gastric schwannoma with pathologically malignant potential surviving two years after laparoscopy-assisted partial gastrectomy. Case Rep Gastroenterol 5: 502-507, 2011.

26. Bees NR, Ng CS, Dicks-Mireaux C and Kiely EM: Gastric malignant schwannoma in a child. Br J Radiol 70: 952-955, 1997.

27. Takemura M, Yoshida K, Takii M, Sakurai K and Kanazawa A: Gastric malignant schwannoma presenting with upper gastrointestinal bleeding: A case report. J Med Case Rep 6: 37, 2012.

28. Aktekın A, Özkara S, Merıç K, Günay Gürleyık M, Aker F and Sağlam A: Plexiform schwannoma of the duodenum accompanying pyloric stenosis: Report of a case. Turk J Gastroenterol 23: 385-389, 2012.

29. Tahir TM, Anwar S, Naseem N, Mansoor-Ul-Haq H and Saqib M: Gastric schwannoma in a female patient with pulmonary tuberculosis-a clinicopathological assessment and diagnosis. Malays J Med Sci 17: 45-50, 2010.

30. Hong HS, Ha HK, Won HJ, Byun JH, Shin YM, Kim AY, Kim PN, Lee MG, Lee GH and Kim MJ: Gastric schwannomas: Radiological features with endoscopic and pathological correlation. Clin Radiol 63: 536-542, 2008.

31. Atmatzidis S, Chatzimavroudis G, Dragoumis D, Tsiaousis P, Patsas A and Atmatzidis K: Gastric schwannoma: A case report and literature review. Hippokratia 16: 280-282, 2012.

32. Tan AC, Tan CH, Nandini C and Ng CY: Multimodality imaging features of rectal schwannoma. Ann Acad Med Singap 41: 476-478, 2012.

33. Fernández-Esparrach G, Sendino O, Solé M, Pellisé M, Colomo L, Pardo A, Martínez-Pallí G, Argüello L, Bordas JM, Llach $\mathrm{J}$ and Ginès A: Endoscopic ultrasound-guided fine-needle aspiration and trucut biopsy in the diagnosis of gastric stromal tumors: A randomized crossover study. Endoscopy 42: 292-299, 2010.

34. Funasaka K, Miyahara R, Furukawa K, Sawada T, Maeda K, Yamamura T, Ishikawa T, Ohno E, Nakamura M, Kawashima H, et al: Mutation analysis of gastrointestinal stromal tumors using RNA obtained via endoscopic ultrasound-guided fine-needle aspiration. Transl Oncol 13: 100848, 2020.

35. Stock K, Hann von Weyhern C, Slotta-Huspenina J, Burian M, Clevert DA, Meining A, Prinz C, Pachmann C, Holzapfel K, Schmid RM and Lersch C: Microcirculation of subepithelial gastric tumors using contrast-enhanced ultrasound. Clin Hemorheol Microcirc 45: 225-232, 2010.

36. Fujii Y, Taniguchi N, Hosoya Y, Yoshizawa K, Yasuda Y, Nagai $\mathrm{H}$ and Itoh K: Gastric schwannoma: Sonographic findings. J Ultrasound Med 23: 1527-1530, 2004.

37. Gallo SH and Sagatelian MA: Benign schwannoma of the small intestine: An unusual cause of gastrointestinal bleeding. J Ky Med Assoc 93: 291-294, 1995.

38. Levy AD, Quiles AM, Miettinen M and Sobin LH: Gastrointestinal schwannomas: CT features with clinicopathologic correlation. AJR Am J Roentgenol 184: 797-802, 2005.

39. Takeda M, Amano Y, Machida T, Kato S, Naito Z and Kumita S: CT, MRI, and PET findings of gastric schwannoma. Jpn J Radiol 30: 602-605, 2012.

40. Komatsu D, Koide N, Hiraga R, Furuya N, Akamatsu T, Uehara T and Miyagawa S: Gastric schwannoma exhibiting increased fluorodeoxyglucose uptake. Gastric Cancer 12: 225-228, 2009.

41. Miyake KK, Nakamoto Y, Kataoka TR, Ueshima C, Higashi T, Terashima T, Nakatani K, Saga T, Minami S and Togashi K: Clinical, morphologic, and pathologic features associated with increased FDG uptake in schwannoma. AJR Am J Roentgenol 207: 1288-1296, 2016.

42. Hsu KF, Lin CT, Wu CC, Hsiao CW, Lee TY, Mai CM, Jin JS and Jao SW: Schwannoma of the rectum: Report of a case and review of the literature. Rev Esp Enferm Dig 102: 289-291, 2010.

43. Çakır T, Aslaner A, Yaz M and Gündüz U: Schwannoma of the sigmoid colon. BMJ Case Rep 2015: bcr2014208934, 2015.

44. Fukuchi M, Naitoh H, Shoji H, Yamagishi J, Suzuki M, Yanoma T, Kiriyama S and Kuwano H: Schwannoma of the stomach with elevated preoperative serum carbohydrate antigen 19-9: Report of a case. Surg Today 42: 788-792, 2012.

45. Shu Z, Li C, Sun M and Li Z: Intestinal schwannoma: A clinicopathological, immunohistochemical, and prognostic study of 9 cases. Gastroenterol Res Pract 2019: 3414678, 2019. 
46. Tozbikian G, Shen R and Suster S: Signet ring cell gastric schwannoma: Report of a new distinctive morphological variant. Ann Diagn Pathol 12: 146-152, 2008.

47. Hou YY, Tan YS, Xu JF, Wang XN, Lu SH, Ji Y, Wang J and Zhu XZ: Schwannoma of the gastrointestinal tract: A clinicopathological, immunohistochemical and ultrastructural study of 33 cases. Histopathology 48: 536-545, 2006.

48. Chetty R: Reticular and microcystic schwannoma: A distinctive tumor of the gastrointestinal tract. Ann Diagn Pathol 15: 198-201, 2011.

49. Schwartz DA: Malignant schwannoma occurring with Schistosoma japonicum: A case report. Southeast Asian J Trop Med Public Health 13: 601-605, 1982.

50. Bodner E and De los Santos EV: The malignant degeneration of a rectal neurinoma; 'views on the tendency of the tumors of the nerve sheaths towards malignant degeneration'. Philipp J Surg Surg Spec 20: 125-141, 1965.

51. Wang CL, Neville AM, Wong TZ, Hall AH, Paulson EK and Bentley RC: Colonic schwannoma visualized on FDG PET/CT. Clin Nucl Med 35: 181-183, 2010.

52. Catania G, Puleo C, Cardì F, Catalano F, Iuppa A and Buffone A: Malignant schwannoma of the rectum: A clinical and pathological contribution. Chir Ital 53: 873-877, 2001.

53. Tomica D, Danolić D, Puljiz M, Alvir I, Mamić I, Milas I, Knezević F and Banović M: Aggressive intestinal schwannoma malignum mimicking gynecological pathology-A case report. Coll Antropol 35 (Suppl 1): S339-S343, 2011.

54. Weiss SW, Langloss JM and Enzinger FM: Value of S-100 protein in the diagnosis of soft tissue tumors with particular reference to benign and malignant Schwann cell tumors. Lab Invest 49: 299-308, 1983.

55. Tao K, Chang W, Zhao E, Deng R, Gao J, Cai K, Wang G and Zhang P: Clinicopathologic features of gastric schwannoma: 8 -year experience at a single institution in China. Medicine (Baltimore) 94: e1970, 2015.

56. Şahin S, Ekinci Ö, Seçkin S and Dursun A: The diagnostic and prognostic utility of DOG1 expression on gastrointestinal stromal tumors. Turk Patoloji Derg 33: 1-8, 2017.

57. Povoski SP and Chang WW: Gastric schwannoma found incidentally 19 years after a horizontal gastroplasty for morbid obesity. Obes Surg 11: 762-765, 2001.

58. Terada T: Schwannoma and leiomyoma of the colon in a patient with ulcerative colitis. J Gastrointest Cancer 47: 328-330, 2016.
59. Kikuchi S, Nishizaki M, Kuroda S, Tanabe S, Noma K, Kagawa S, Shirakawa Y, Kato H, Okada H and Fujiwara T: Nonexposure laparoscopic and endoscopic cooperative surgery (closed laparoscopic and endoscopic cooperative surgery) for gastric submucosal tumor. Gastric Cancer 20: 553-557, 2017.

60. Ramai D, Lai J, Changela K, Reddy M and Shahzad G: Transverse colon schwannoma treated by endoscopic mucosal resection: A case report. Mol Clin Oncol 7: 830-832, 2017.

61. Cai MY, Zhu BQ, Xu MD, Qin WZ, Zhang YQ, Chen WF, Ooi M, Li QL, Yao LQ and Zhou PH: Submucosal tunnel endoscopic resection for extraluminal tumors: A novel endoscopic method for en bloc resection of predominant extraluminal growing subepithelial tumors or extra-gastrointestinal tumors (with videos). Gastrointest Endosc 88: 160-167, 2018.

62. Fukunaga Y, Tamegai Y, Chino A, Ueno M, Nagayama S, Fujimoto Y, Konishi T and Igarashi M: New technique of en bloc resection of colorectal tumor using laparoscopy and endoscopy cooperatively (laparoscopy and endoscopy cooperative surgery-colorectal). Dis Colon Rectum 57: 267-271, 2014.

63. Huang JL, Zheng ZH, Wei HB, Chen TF, Liu JP, Huang Y, Wei B and Fang JF: Endoscopy-assisted laparoscopic resections for gastric gastrointestinal stromal tumors: A retrospective study. J Laparoendosc Adv Surg Tech A 27: 110-114, 2017.

64. Hu BG, Wu FJ, Zhu J, Li XM, Li YM, Feng Y and Li HS: Gastric schwannoma: A tumor must be included in differential diagnoses of gastric submucosal tumors. Case Rep Gastrointest Med 2017: 9615359, 2017.

65. Huang V, Bergner AL, Halpin C, Merker VL, Sheridan MR, Widemann BC, Blakeley JO and Plotkin SR: Improvement in patient-reported hearing after treatment with bevacizumab in people with neurofibromatosis type 2. Otol Neurotol 39: 632-638, 2018. 